\title{
Recurrent Ischemic Cerebrovascular Accidents with Recurrent Acute Ischemia of the Left Upper Limb Revealing Acute Myeloid Leukemia
}

Ben Jmaa Hela ${ }^{1^{*}}$, Masmoudi Sayda ${ }^{1}$, Ghorbel Nesrine ${ }^{1}$, Djmal Hassen ${ }^{1}$, Gueldich Majdi ${ }^{1}$, Abdi Ayda $^{1}$, Souissi Iheb ${ }^{2}$ and Frikha Imed ${ }^{1}$

${ }^{1}$ Department of Cardiovascular and Thoracic Surgery, Habib Bourguiba Hospital Sfax, Tunisia

${ }^{2}$ Department of Anesthesiology, Habib Bourguiba Hospital Sfax, Tunisia

"Corresponding author: Ben Jmaa Hela, Department of Cardiovascular and Thoracic Surgery, Habib Bourguiba Hospital Sfax, Tunisia, Tel: 0021696704740; E-mail: bjhela@yahoo.fr

Rec date: Jun 16, 2015; Acc date: Jul 07, 2015; Pub date: Jul 09, 2015

Copyright: @ 2015 Hela BJ. This is an open-access article distributed under the terms of the Creative Commons Attribution License, which permits unrestricted use, distribution, and reproduction in any medium, provided the original author and source are credited.

\begin{abstract}
Acute and recurrent ischemic episodes in multiple vascular territories in acute leukemia are unusual and rare. Only some cases have been reported. In most of these cases, the diagnosis was acute promyelocytic leukemia (type 3).

We report in this paper a case of acute myeloid leukemia (type 1) revealed by acute upper limb ischemia associated to recurrent stroke in a 55 year-old patient.
\end{abstract}

Keywords: Acute ischemia; Acute leukemia; Surgical embolectomy

\section{Introduction}

Ischemic complications of myeloid acute leukemia are rare. A few cases have been reported in the literature.

The majority of reported cases were acute myeloid promyelocytic leukemia $[1,2]$. We report a case of acute myeloid leukemia revealed by recurrent acute upper limb ischemia and recurrent ischemic cerebrovascular accidents.

\section{Case presentation}

We report the case of a 55 year-old man, with no risk factors of atherosclerosis, who was admitted to the department of neurology for dysarthria, and headache. The neurological examination was normal.

A cerebral CT scan showed vertebral basilar ischemic lesions. The electrocardiogram revealed a sinus rhythm.

During his hospital stay, he developed a sudden pain with a coldness of the left upper limb. Clinical examination revealed a cold limb with cyanotic fingers. All the pulses were abolished. The pulses of the right upper limb and the lower limbs were present. So, he underwent emergent surgery for acute upper limb ischemia. He underwent embolectomy through a surgical access of the brachial artery under a local anesthesia. The desobstruction with a Fogarty catheter took off a white thrombus from the subclavian artery. After the surgery, the limb became warm and all the pulses reappeared. A curative anticoagulation with heparin was introduced immediately after the operation. A biological control of the anticoagulant treatment was satisfactory. Laboratory exams did not reveal any abnormality.

Five hours later, he presented the same clinical signs of upper left limb necessitating a second desobstruction with a Fogarty catheter.

The thrombus removed had the same aspect.
Because of recurrence of systemic embolic events, an embolic heart disease was suspected, but excluded by an echocardiography which showed no anomalies. Twelve hours later, he presented another episode of ischemia of the same limb. CT scan revealed a thrombus of $16 \mathrm{~mm}$ in the left subclavian artery without atheroma (Figure 1).

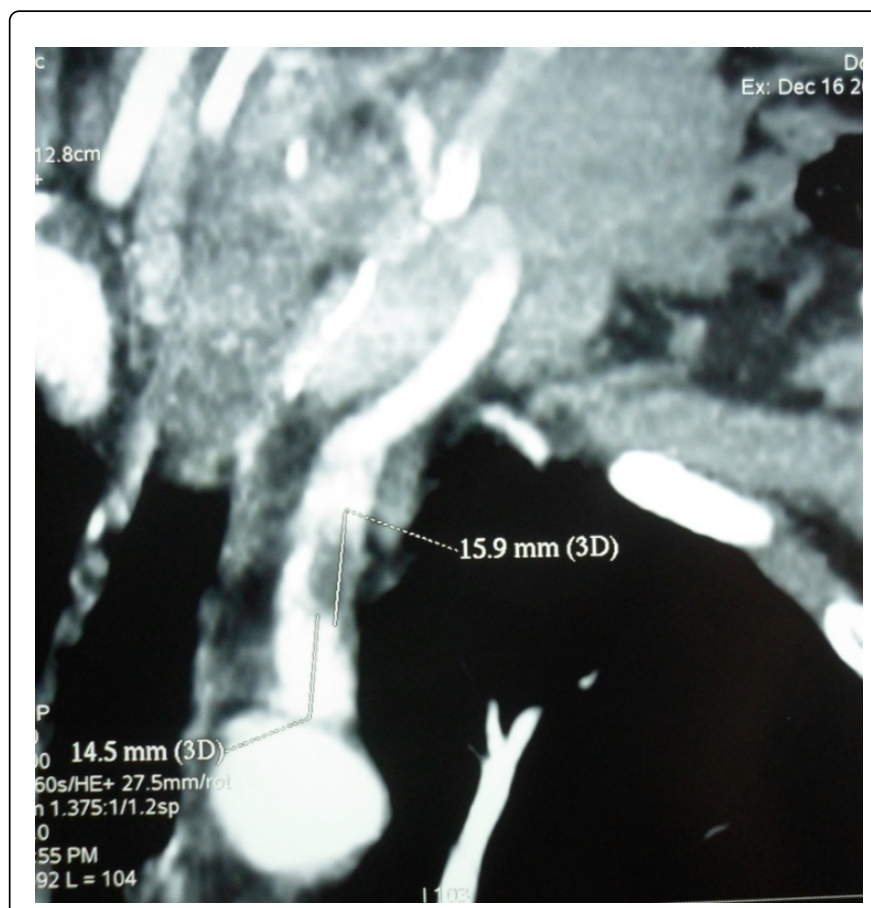

Figure 1: Tomographie aspect of endoluminal thrombosis of the subclavian artery (arrow).

So, the patient underwent surgery through a left posterolateral thoracotomy in the fourth intercostal space to have an access to the 
Citation: Hela BJ, Sayda M, Nesrine G, Hassen D, Majdi G, et al. (2015) Recurrent Ischemic Cerebrovascular Accidents with Recurrent Acute Ischemia of the Left Upper Limb Revealing Acute Myeloid Leukemia . J Vasc Med Surg 3: 209. doi:10.4172/2329-6925.1000209

Page 2 of 3

subclavian artery. A white thrombus was removed from the artery (Figures 2 and 3). The aortic wall was smooth without atheroma. The post-operative biology revealed a leukocytosis with thrombocytopenia and blasts in the blood. The diagnosis of acute myeloid leukemia was confirmed by the detection of myeloblasts in the myelogram. A treatment by chemotherapy was indicated but the patient died before the treatment by a respiratory distress.

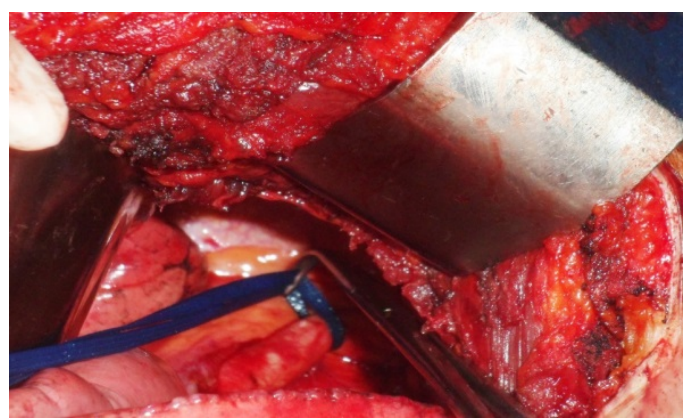

Figure 2: Intraoperative view of the left subclavian artery via a left thoracotomy.

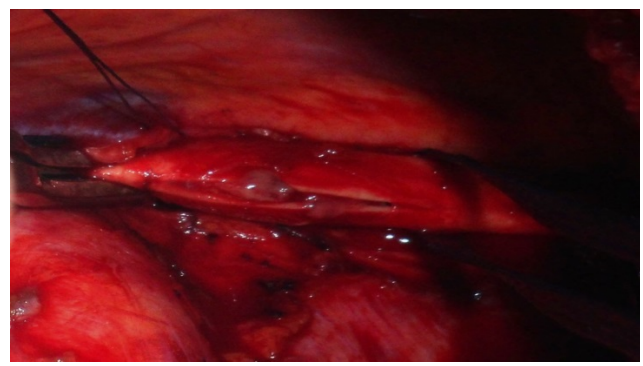

Figure 3: Intraoperative view of thrombus of the left subclavian artery (arrow).

\section{Discussion}

Acute myeloid leukemia is a hemopoietic myeloid stem cell neoplasm characterized by the rapid growth of abnormal white blood cells that accumulate in the bone marrow and interfere with the production of normal blood cells [3]. Patients with acute myeloid leukemia present with symptoms resulting from bone marrow failure or organ infiltration with leukemic cells [4]. Typical symptoms include asthenia, dyspnea, malaise, dizziness, fever, pallor, bleeding gums, or epistaxis. Physical examination reveals usually hepatosplenomegaly, lymphadenopathy, and bone pain [4]. Leukocytosis associated with circulating blasts, and myeloblasts in the myelogram confirm the diagnosis. Hyperleukocytosis has a deleterious effect on blood rheology and obstruction of small vessels, so it causes a decreased tissue perfusion $[4,1]$.

Obstruction of great vessels is rarely revealing this disease [5]. It may be caused by accumulation of blasts in the blood with platelet aggregation [1,6-9] or activation of the coagulation process [10,9]. The most common locations for ischemic injury are the central nervous system and the respiratory system [4]. When the ischemia occurs in the brain it may lead to stroke. The recurrence of ischemic events in patients without embolic heart disease and without atherosclerosis risk factors must be evocative of malignant blood disease. In a review of the literature, John Overton [11,12] reported thirteen cases of limb ischemia revealing promyelocytic leukemia. Many cases of acute myocardial infarction without coronary atherosclerosis have been reported [13].

De Stefano et al. [14] recruited 379 consecutive adult patients with acute leukemia. At diagnosis, thrombosis was a presenting manifestation in $3.2 \%$ in other acute myeloid leukemia patients. The originality of the case is the type 1 of leukemia is and the multiple locations of ischemic attacks. The emergent treatment of these ischemic events is surgical revascularization by embolectomy.

In the postoperative period, the risk of recurrence is high. So, the chemotherapy must be started as soon as the diagnosis is done $[11,15,16]$. It reduces the rate of blasts in the blood, and reduces the risk of recurrence of embolism [12].

\section{Conclusion}

In acute myeloid leukemia, hyperleukocytosis resuts in increasing of blood rheology and deterioration of tissue perfusion.

In case of recurrence of ischemic accidents in a patient without cardiac disease and without risk factors of atherosclerosis, we must think to acute myeloid leukemia in order to begin the treatment with chemotherapy which improves the prognosis and decreases the risk of ischemic events recurrence.

\section{References}

1. Azghari A, Boukhbrine MK, Tijani Y, Bouziane Z, Idrissi R, et al. (2010) Acute lower limb ischemia revealing acute leukemia. Case report and review of the literature. J Mal Vasc 35: 43-46.

2. Rashidi A, Silverberg ML, Conkling PR, Fisher SI (2013) Thrombosis in acute promyelocytic leukemia. Thromb Res 131: 281-289.

3. Leptidis J, Aloizos S, Chlorokostas P, Gourgiotis S (2014) Fatal cardiac tamponade as the first manifestation of acute myeloid leukemia. Am J Emerg Med 32: 1294.

4. Antonio E Muñiz (2012) Myocardial infarction and stroke as the presenting symptoms of acute myeloid leukemia. The Journal of Emergency Medicine 42: 651-654.

5. Reisch N, Roehnisch T, Sadeghi M, Greiner L, Regenbogen C, et al. (2007) AML M1 presenting with recurrent acute large arterial vessel thromboembolism. Leuk Res 31: 869-871.

6. Kootte AM, Thompson J, Bruijn JA (1986) Acute myelocytic leukemia with acute aortic occlusion as presenting symptom. Acta Haematol 75: 120-121.

7. Redmond EJ, Welch M, Durrans D, Carr HM, Chasty R, et al. (1993) Acute ischaemia of the lower limb: an unusual presenting feature of acute lymphoblastic leukaemia. Eur J Vasc Surg 7: 750-752.

8. Fass R, Haddad M, Zaizov R, Sandbank Y, Yaniv I, et al. (1992) Recurrent peripheral arterial occlusion by leukemic cells sedimentation in acute promyelocytic leukemia. J Pediatr Surg 27: 665-667.

9. Kafetzakis A, Foundoulakis A, Ioannou CV, Stavroulaki E, Koutsopoulos A, et al. (2007) Acute lower limb ischemia as the initial symptom of acute myeloid leukemia. Vasc Med 12: 199-202.

10. Rolston DD, Rubin S, Topolsky D, Styler M, Crilley P (1998) Arterial occlusions as a presenting feature of acute promyelocytic leukemia. Am J Clin Oncol 21: 436-437.

11. Kalk E, Goede A, Rose P (2003) Acute arterial thrombosis in acute promyelocytic leukaemia. Clin Lab Haematol 25: 267-270. 
Citation: Hela BJ, Sayda M, Nesrine G, Hassen D, Majdi G, et al. (2015) Recurrent Ischemic Cerebrovascular Accidents with Recurrent Acute Ischemia of the Left Upper Limb Revealing Acute Myeloid Leukemia . J Vasc Med Surg 3: 209. doi:10.4172/2329-6925.1000209

Page 3 of 3

12. Overton J, Nicklin A, Eleftheriou P, Frith D, Gravante G, et al. (2012) Recurrent acute lower-limb ischemia with multiple organ infarctions secondary to acute myeloid leukaemia M1. Ann Vasc Surg 26: 1128.

13. Rogers LR (1991) Cerebrovascular complications in cancer patients Neurol Clin 9: 889-899.

14. De Stefano V, Sorà F, Rossi E, Chiusolo P, Laurenti L, et al. (2005) The risk of thrombosis in patients with acute leukemia: occurrence of thrombosis at diagnosis and during treatment. J Thromb Haemost 3: 1985-1992.
15. Campbell J, Mitchell CA (1994) Acute leg ischaemia as a manifestation of the hyperleukocytosis syndrome in acute myeloid leukaemia. Am J Hematol 46: 167.

16. Mataix R, Gómez-Casares MT, Campo C, Jiménez S, Malcorra JJ (1996) Acute leg ischaemia as a presentation of hyperleukocytosis syndrome in acute myeloid leukaemia. Am J Hematol 51: 250. 